\title{
Physical controls of cold seep methane emission
}

\author{
P. Linke, S. Sommer, L. Rovelli, D.F. McGinnis \\ IFM-GEOMAR, Leibniz Institute of Marine Sciences at the University of Kiel \\ Wischhofstr. 1-3 \\ D-24148 Kiel, Germany
}

\begin{abstract}
In situ methane emission measurements from sediments are combined with water column backscatter anomalies recorded with an Acoustic Doppler Current Profiler (ADCP) integrated on a benthic observatory. During cruise SO191 ${ }^{1}$ to the Hikurangi Margin (New Zealand), the Fluid Flux Observatory (FLUFO) was deployed at a cold seep site at Omakere Ridge. The first 26 hours of in situ incubation revealed low to moderate methane fluxes $\left(0.01\right.$ to $\left.0.4 \mathrm{mmol} \mathrm{m}^{-2} \mathrm{~d}^{-1}\right)$. In the following sampling sequence, however, the methane concentration in the flux chamber reached 3-fold higher concentrations. Simultaneous to the sudden methane increase, a significant backscatter anomaly was recorded and persisted for $30 \mathrm{~min}$ and covered the entire depth range $(100 \mathrm{~m})$ of the upward looking ADCP. Data analyses revealed that a plume outburst likely occurred during this time. A second data set was obtained during lander deployments at Rock Garden where visual observations by ROV confirmed the transient pattern of free gas injection into the water column. Acoustic flares and methane concentration increases in the bottom water hint towards a pressure (tidal) induced discharge mechanism. The presented data demonstrate the temporal and spatial variability of seabed methane emission, and very short methane signal lifetime in the water column (hours) due to turbulent diffusion. Both have to be considered when methane budgets are extrapolated from single methane emission rates.
\end{abstract}

\section{INTRODUCTION}

Natural marine hydrocarbon seeps are important sources of methane $\left(\mathrm{CH}_{4}\right)$ to the surface sediments, the benthic boundary layer (BBL) and eventually to the water column. $\mathrm{CH}_{4}$ is a potent greenhouse gas; per mass unit, it warms the Earth $\sim 23$ times more than carbon dioxide $\left(\mathrm{CO}_{2}\right)$ when averaged over 100 years [1]. Quantifying the discharge of $\mathrm{CH}_{4}$ from the seabed, its fate in the water column and its flux to the atmosphere has therefore been the subject of ongoing research on many different fronts [2].

Seabed fluid flow, also known as submarine seepage, is the migration of gases and liquids through the seabed and into the marine environment. This global geological phenomenon has many implications for the sub-seabed, seabed and benthic ecosystems [3]. Submarine seepage affects seabed morphology (forming pockmarks and mud volcanoes), benthic carbon turnover and ecology - sustaining unique hetero- and chemotrophic seep communities which rely on the supply of reduced inorganic compounds as $\mathrm{H}_{2} \mathrm{~S}$ and $\mathrm{CH}_{4}$ [4]. Because of the biological dependency, it is expected that the chemical

\footnotetext{
${ }^{1}$ Cruise SO191 was part of the COMET project in the framework of the R\&D program GEOTECHNOLOGIEN, both funded by the German Ministry of Education and Research (Grant No: 03G0600D and 03G0191A). Daniel F. McGinnis was supported by Eawag and the Swiss National Science Foundation (Grant 200020-111763).
}

environment and the local hydrodynamics (diffusive, advective, gas bubble transport) influence the species composition and their activity. Still, not much is known about the role of these physical control parameters on the discharge of $\mathrm{CH}_{4}$ from the seabed sediments, across the BBL and into the water column. This BBL is a highly dynamic environment, with the local physics within this layer strongly impacting the flux regime [5].

The occurrence of gas hydrates, fluid and gas seepage from Hikurangi Margin sediments (Fig. 1) has been inferred from a widespread bottom simulating reflection (BSR) [6], methane derived carbonates, gas flares in the water column [7], and the presence of seep fauna [8]. Apart from these geophysical findings and sporadic observations, detailed geochemical studies were lacking [9].

Water column profiles are a common method for locating active seeps or vent sites, and have confirmed $\mathrm{CH}_{4}$ emission at the Hikurangi Margin [7]. Generally, after $\mathrm{CH}_{4}$ is injected into the water column, it is diluted very rapidly, distributed by currents, and is most likely oxidized by microbes in the water [10]. Thus, elevated $\mathrm{CH}_{4}$ concentrations around seeps are usually only a temporal snapshot, as water sampling at the same site within a few hours can produce very different results $[11,12,13]$.

Little is known about sediment release of $\mathrm{CH}_{4}$, and currently, only a few in situ measurements of seabed $\mathrm{CH}_{4}$ emission exist $[14,15,16]$, while other studies mostly rely on model calculations $[17,18]$. For example, large inconsistencies exist between emission rates measured in situ and fluxes derived from numerical modelling of pore water gradients for cold seep sites at Hydrate Ridge. Moreover, methane expulsion and seep distribution are extremely variable, which further impedes methane flux estimates $[19,20]$.

Furthermore, the impact and overall relevance of the complex physical control parameters on benthic flux rates of fluids and free gas are not well constrained. Hydrologic studies have primarily contributed to our understanding of long-term, relatively steady-state processes including chemical mass balance, geopressure production and relief, and lithospheric cooling rates. However, short-period physical forcing also occurs due to, for example, tidal oscillations and waves, and episodic events such as tsunamis, gas discharge, and seismic and aseismic strain [21, 22, 23].

Water and free gas release (bubbles) are common phenomena around cold seeps, which may be related to gas hydrate deposits, mud volcanoes, pockmarks or a mixture of those [3]. Bubbles can be easily detected by hydroacoustics 
because of the density difference between gas and water [19]. The hydroacoustic bubble-release signature can sometimes be viewed as a "flare", which refers to the flame-like image produced on hydrographs or backscatter plots. Acoustic flares only indicate the presence of scatterers (bubbles, particles) in the water, but reveal nothing about the hydrodynamics.

Hydrodynamically, a large volume of gas release can create a "plume". For the purposes of this discussion, a plume is defined as a vertical advective flow of water driven by a positive buoyancy source which can be bubbles (two-phase), heat, less saline water, dissolved $\mathrm{CH}_{4}$, or any combination (single-phase). A bubble stream is simply rising bubbles in a row, without necessarily inducing a significant vertical water velocity.

Methane bubbles released from seeps will dissolve rapidly in the water column $[24,25,26]$, however massive gas releases create upwelling and forms a bubble plume which can transport significant amounts of methane into the water column and possibly to the atmosphere [27, 28, 13, 29]. Unfortunately, such bubble eruptions are difficult to study as they are transient and highly intermittent [19]. Therefore, the aim of our present study was to determine the spatial and temporal variability of in situ fluxes of $\mathrm{CH}_{4}$ (dissolved and free gas) from different cold seep sites at the Hikurangi Margin.

We present data from lander deployments at two Hikurangi Margin cold seep sites which were studied during RV SONNE cruise SO191 in February/March 2007 [9] and show evidence of large-scale activity at two different sites observed using various in situ technologies. One site showed a distinct outburst of fluid (with a smaller bubble outburst in between) whereas the other site shows distinct tidal activity in the formation of presumed bubble streams (possibly plumes?) detaching from the seabed. These deployments provided a unique combination of biological, chemical and physical data collected simultaneously at the BBL and enable new perspectives on methane source strength of cold seep sites, its controls and the monitoring of the fate of methane in the water column.

\section{Regional Setting}

The Hikurangi Margin at the east coast of New Zealand's North Island is characterized by the oblique subduction of the Pacific plate beneath the Australian plate (Fig. 1). A detailed description of the tectonic and geologic framework for gas hydrates and cold seeps on the Hikurangi margin is provided by Ref. [30]. We focus on two study sites; Bear's Paw at the Omakere Ridge, and Faure Site at Rock Garden.

1) Bear's Paw (Omakere Ridge): Bear's Paw is a cold seep structure on the Omakere Ridge (Fig. 1) west of Ritchie Ridge that was discovered in 2007 during SO191 [31]. On the sidescan sonar images obtained during SO191, Bear's Paw is well expressed. Ground-truthing by subsequent TV sled surveys, sampling by TV-guided grab and coring equipment testified to the presence of carbonate crusts, seep-associated fauna and hydrate layers [31].
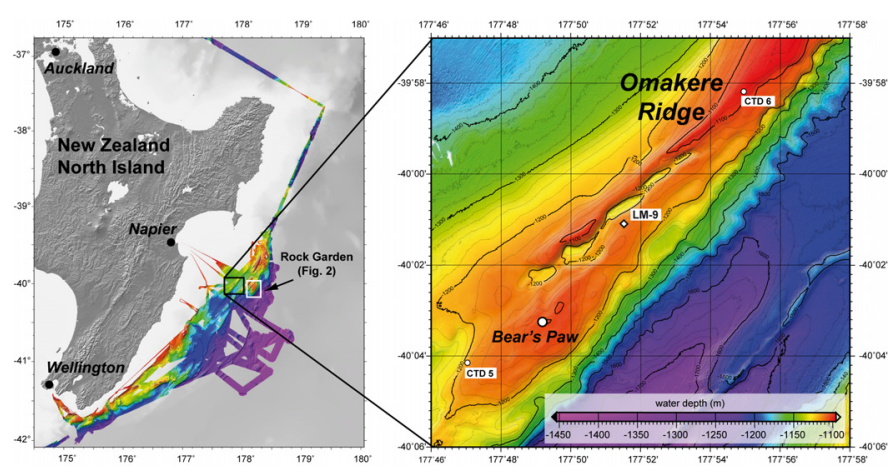

Figure 1. Overview map showing the bathymetry of the Hikurangi Margin at the east coast of New Zealand's North Island mapped during SONNE cruise SO191. The enlarged bathymetric map depicts Omakere Ridge with the LM-9 site [8], two CTD stations $(5,6)$ marking the endpoints of an intense CTD survey [9] and the Bear's Paw cold seep site with the stations relevant for this paper (maps courtesy J. Greinert).

2) Faure Site (Rock Garden): Rock Garden (Fig. 2), as it is known by local fishermen, is the southern termination of Ritchie Ridge uplifted by the subduction of a seamount beneath the outer margin bank [30]. Several spots of active gas discharge were observed with the ROV [20], allowing accurate planning of lander deployments.

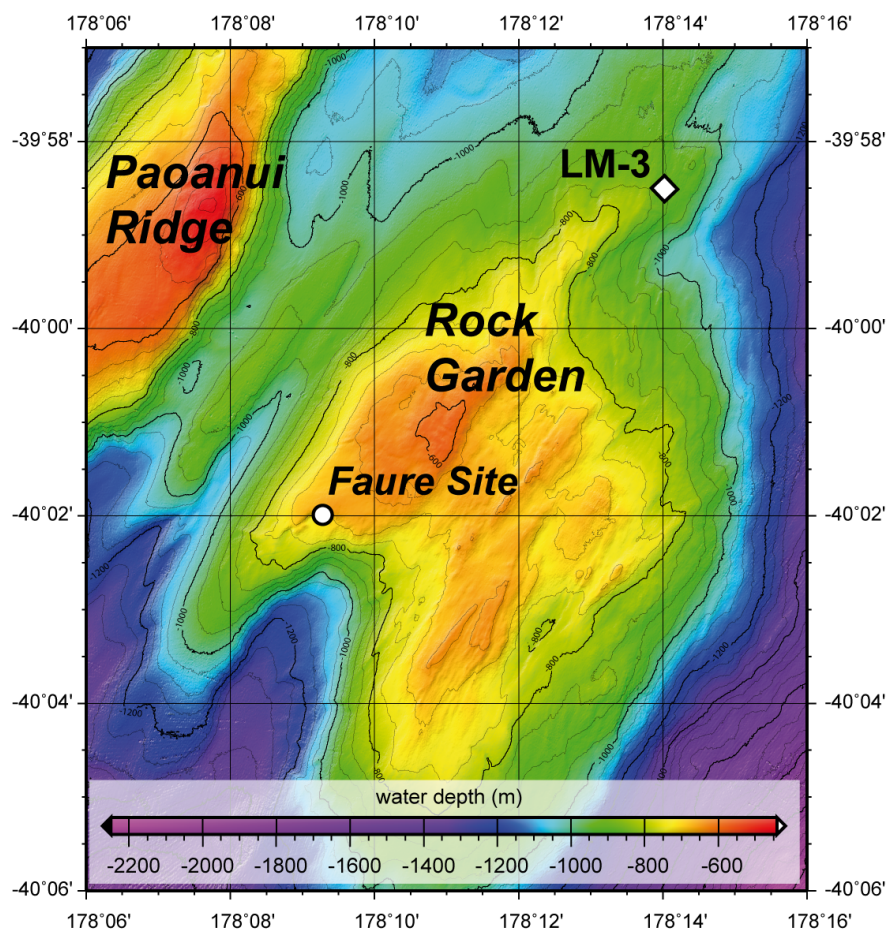

Figure 2. Detailed bathymetric map of the Rock Garden area with the Faure Site and LM-3 site [8]. The landers were deployed at Faure Site close to a site of vigorous gas discharge (Faure bubble site) discovered during ROV dive 2 [20] as shown in Fig. 5 (map courtesy J. Greinert).

\section{MATERIAL AND MEthodS}

\section{A. In-situ Flux Measurements}

Benthic landers provide a stationary study environment decoupled from the movement of the ship, and simultaneously 
measure several physical, chemical and biological parameters across the sediment water interface. The Biogeochemical Observatory (BIGO) and the Fluid Flux Observatory (FLUFO) $[32,16]$ were deployed for in-situ flux measurements of methane and oxygen. For more detailed information see Fig. 3 and Ref. [33].
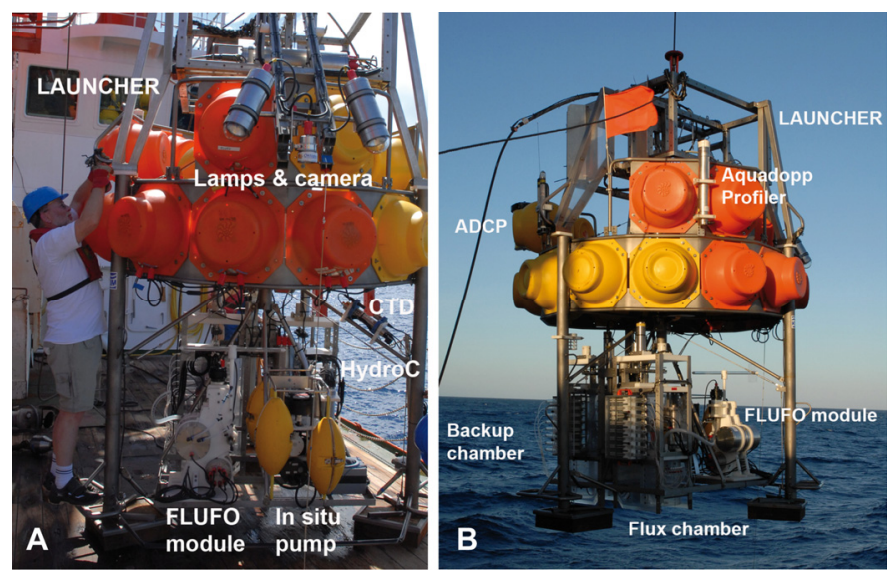

Figure 3. Fluid Flux Observatory (FLUFO) prepared for video-guided deployment with the Launcher. A) The front and (B) back view show the different modules integrated into FLUFO.

Each observatory is equipped with two circular chambers (internal diameter $28.8 \mathrm{~cm}$ ), each covering a sediment area of $651.4 \mathrm{~cm}^{2}$. A TV-guided launching system allowed smooth placement of the observatories at selected sites on the sea floor (Fig. 3). Sampling details and analytical procedures are described by Ref. [33].

\section{B. Measurement of Physical Control Parameters}

Beside the two benthic chambers, FLUFO (Fig. 3) was equipped with an Acoustic Doppler Current Profiler $(300 \mathrm{kHz}$ Workhorse Sentinel ADCP, Teledyne RD Instruments, USA) and a small CTD (Conductivity, Temperature, Depth; XR420,
RBR Ltd., Ottawa, Canada) mounted $1.2 \mathrm{~m}$ above the seafloor. The CTD was also equipped with an optical backscatter sensor (SeaPoint) which measures light scattered by particles suspended in water. The ADCP was mounted on the lander upward looking in $2.5 \mathrm{~m}$ distance from the seafloor and deployed in standard profiling mode (mode 1 with a theoretical range of $114.7 \mathrm{~m}$ from the bottom). Details of the data processing and analysis are given by Ref. [33].

\section{RESULTS}

\section{A. Lander Deployment at Bear's Paw}

Sediments $(\sim 3 \mathrm{~cm})$ recovered from the flux chamber during FLUFO deployment at Bear's Paw (FLUFO-1) contained many small and larger tubeworms; juvenile bivalves of the genus Acharax and some juvenile clams. Sulfide concentrations in the pore water were up to $5.6 \mu \mathrm{M}$ in the flux chamber (data not shown).

Water samples obtained from the overlying water during the first 26 hours of incubation at Bear's Paw revealed low to moderate $\mathrm{CH}_{4}$ fluxes in the backup and flux chamber, respectively. In the following sample, however, the $\mathrm{CH}_{4}$ concentration of the flux chamber jumped 3-fold to a flux rate of $0.9 \mathrm{mmol} \mathrm{m}^{-2} \mathrm{~d}^{-1}$ whereas the $\mathrm{CH}_{4}$ concentration in the backup chamber remained low and constant at a mean flux rate of $0.01 \mathrm{mmol} \mathrm{m}^{-2} \mathrm{~d}^{-1}$.

At the same time of the large increase of the $\mathrm{CH}_{4}$ concentration (Fig. 4B), an increase in the backscatter strength of the upward-looking ADCP was recorded at around hour 34 (Fig. 4A). The 'flare' (presumed to be bubbles) persisted for $30 \mathrm{~min}$ and covered the entire acoustic depth range $(100 \mathrm{~m})$ of the ADCP. During this period, there is an associated increase in vertical velocity at 34 hours (Fig. 4D - green line), though this may be an artifact from the large backscatter signal in a single beam. No remarkable or associated signal was observed

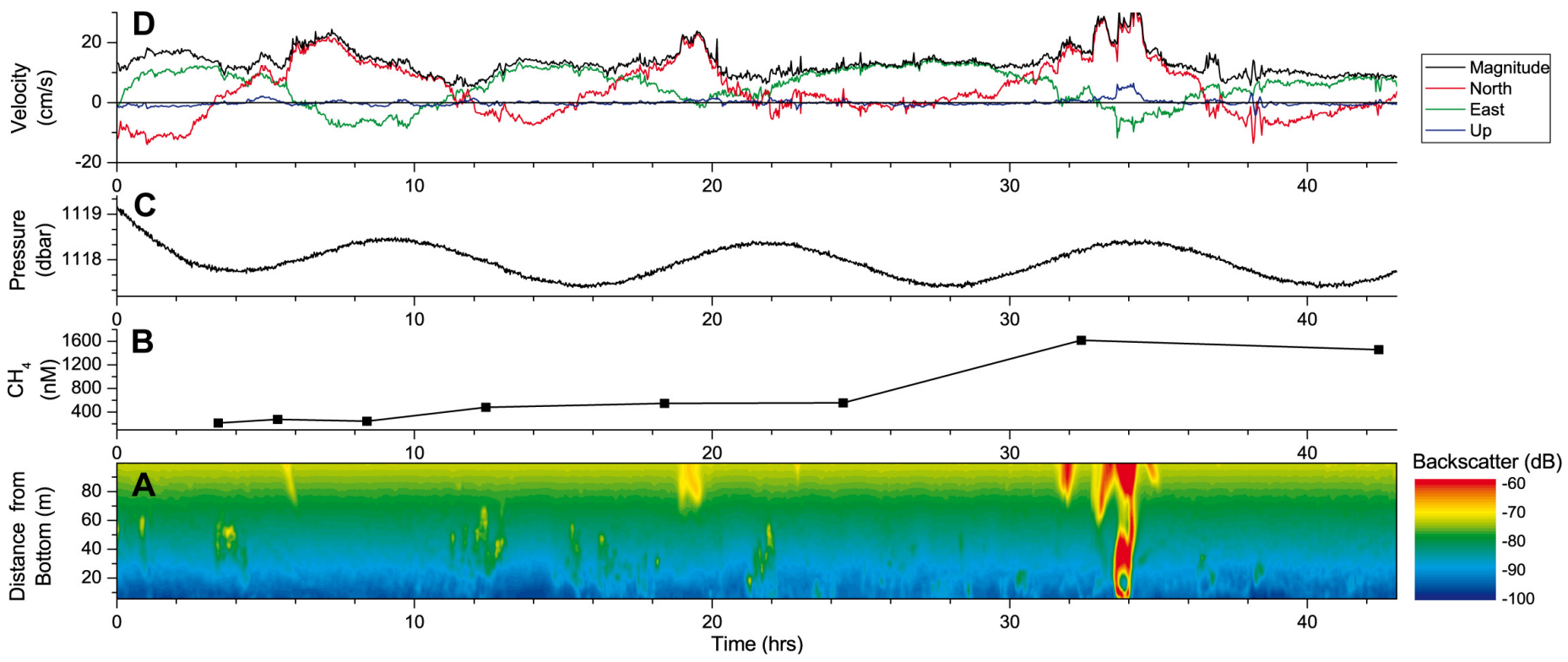

Figure 4. Physical measurements obtained simultaneously to the changes in $\mathrm{CH}_{4}$ concentration during deployment of FLUFO-1. Bottom to top: A) ADCP backscatter intensity (Beam 2), B) time series of $\mathrm{CH}_{4}$ concentrations in the flux chamber, C) pressure and D) depth averaged velocity time series. 
in the turbidity data obtained from the same CTD (not shown).

The flare does not seem to be related to a sudden or tidal hydrostatic pressure drop (Fig. 4C). In fact, the onset of this outburst occurred during high tide and at maximum current velocities of more than $20 \mathrm{~cm} \mathrm{~s}^{-1}$ (Fig. 4D). As there is no increase in suspended particles (inferred from the turbidity data), the acoustic flare in the ADCP during the deployment of the lander is almost definitely attributed to a gas or fluid outburst.

\section{B. Lander Deployments at Faure Site}

As the name Rock Garden implies most of the sediments were underlayed by massive carbonate pavements. These 'rocks' made it extremely difficult to find suitable locations with sufficient sediment cover for penetration of the chambers and recovery of the incubated sediments. Visual inspection of the landers by ROV confirmed that this was the reason why during FLUFO-4, $\sim 11 \mathrm{~cm}$ of sediment was recovered in the backup chamber only. The lander was tilted as one side became uplifted when the penetration of the flux chamber was stopped by the hard ground.

Furthermore, the ROV inspection revealed that the lander was deployed in the immediate vicinity of a gas seep (Fig. 5). The sediment core retrieved from the backup chamber of FLUFO-4 expanded after recovery, indicating the presence of free gas. The pore water profiles showed a sharp increase in sulfide (104.4 to $2159.1 \mu \mathrm{M})$ and alkalinity values (5.1 to 18.4 $\mathrm{mEq} \mathrm{kg}^{-1}$ ) from $4 \mathrm{~cm}$ to $11 \mathrm{~cm}$ sediment depth, respectively (data not shown).

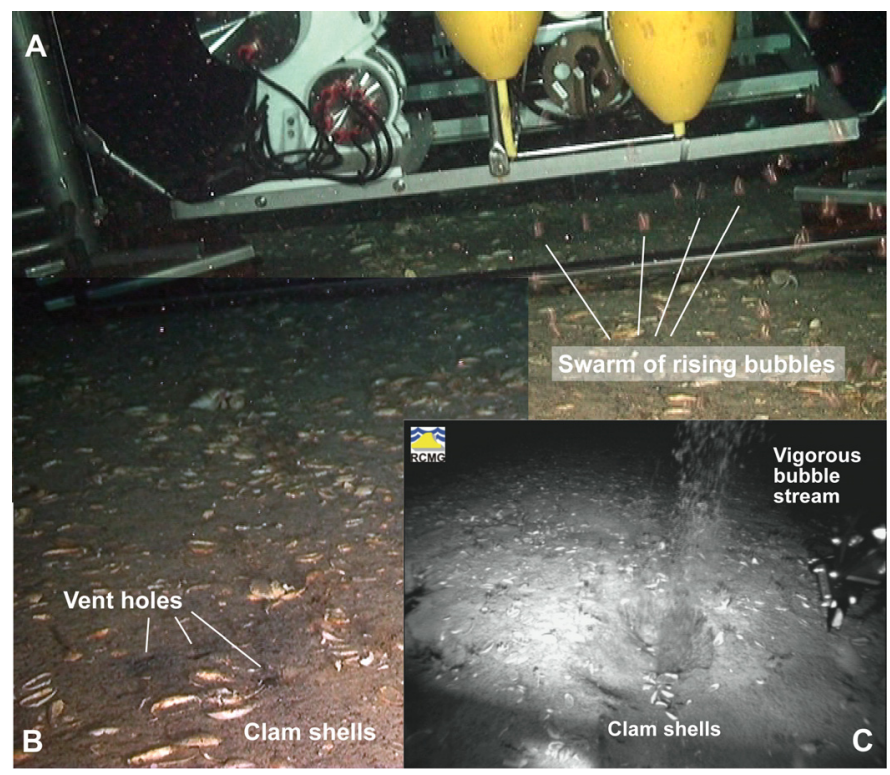

Figure 5. Composite screen captures from video recorded during ROV dive 6. A) FLUFO-4 is deployed at the Faure Site in immediate vicinity to BIGO-4.

B) In front of the observatory shells of vesicomyid clams and vent holes discharging gas bubbles are visible. C) Screen capture of vigorous gas bubbles discharge at Faure bubble site (picture courtesy L. Naudts).

The deployment of BIGO-4 was almost in parallel to the deployment of FLUFO-4 and located approximately $20 \mathrm{~m}$ away. Water from the overlying water of the backup chamber (FLUFO-4) and the ambient bottom water (BIGO-4) showed highly variable $\mathrm{CH}_{4}$ concentrations during these two parallel deployments (Fig. 6B). The $\mathrm{CH}_{4}$ concentration in the enclosed bottom water of the FLUFO-4 backup chamber began with a

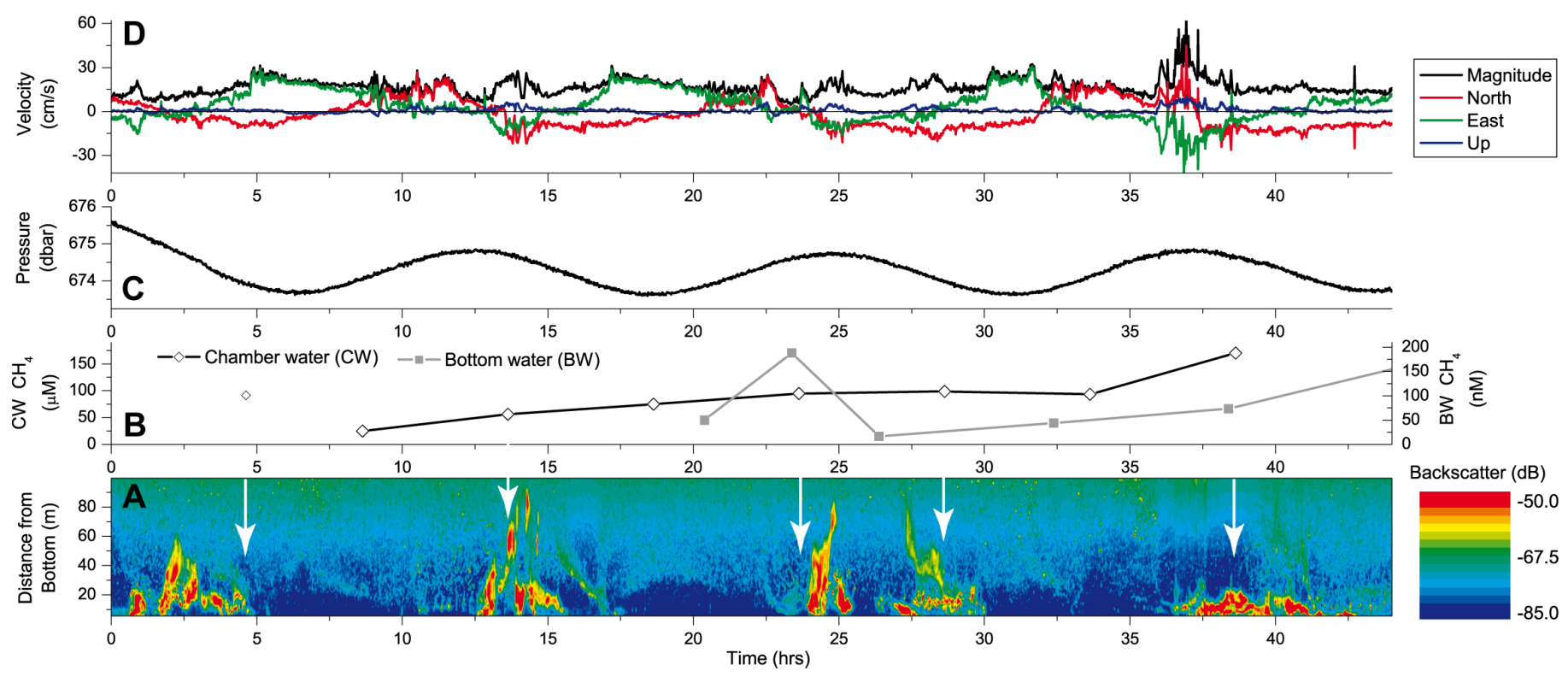

Figure 6. Physical measurements obtained simultaneously to the changes in $\mathrm{CH}_{4}$ concentration during deployment of FLUFO-4. Bottom to top: A) ADCP backscatter (beam 4), B) $\mathrm{CH}_{4}$ concentration in the enclosed chamber water (CW) and the ambient bottom water (BW), C) local hydrostatic pressure with changes, and D) depth-averaged velocity time series. 
peak of $91.5 \mu \mathrm{mol} \mathrm{L} \mathrm{L}^{-1}$, declined rapidly to $24.9 \mu \mathrm{mol} \mathrm{L}^{-1}$ and then increased almost steadily in subsequent samples to 170 $\mu$ mol L $\mathrm{L}^{-1}$. The first peak may be an artifact due to the penetration of gas-charged sediments by the chamber. Therefore, only subsequent samples were used to calculate the $\mathrm{CH}_{4}$ flux of $22.2 \mathrm{mmol} \mathrm{m}^{-2} \mathrm{~d}^{-1}$.

Compared to these high values from inside the chamber, the samples obtained from the ambient bottom water during BIGO-4 deployment show two distinct peaks with $\mathrm{CH}_{4}$ concentrations of 189 and $190 \mathrm{nmol} \mathrm{L}^{-1}$, respectively (Fig. $6 \mathrm{~B})$. The second peak matches with the increase in the bottom water $\mathrm{CH}_{4}$ in the backup chamber of FLUFO-4.

Visual inspection of the landers by ROV [20] showed that the deployment sites were indeed in the immediate vicinity of vent holes discharging free gas (Fig. 5), which is clearly reflected in the backscatter data of the uplooking ADCP mounted on FLUFO (Fig. 6A). The backscatter data show pulses of activity that lasted for 2-4 hours and reached up to $\sim 90 \mathrm{~m}$ above the seafloor. These pulses correlate to a decreasing slope of the pressure readings (Fig. 6C) from the storage CTD mounted on the lander, that is, flares occur during negative slopes of the pressure curve. These flares occur every $\sim 12$ hours along with tides. Flares also occur as east velocity is changing from negative to positive (which may account for the "bended" appearance of the flare), further indicating tidal influence.

\section{DISCUSSION}

We presented two cases from two different sites (Bear's Paw and Faure Site) as examples of the importance of physical processes on fluxes in the benthic boundary layer. At Faure Site (Fig. 6), $\mathrm{CH}_{4}$ concentration fluctuations were documented in both the ambient bottom water and the chamber water, which coincide with tidally induced fluctuations of currents and acoustic backscatter flares, where gas seep activity was clearly evident [20]. Reference [34] describe hydro-acoustic bubble flares in the water column and interpret high-amplitude seismic reflections, extending from a shallow BSR towards the seafloor, as preferred gas migration pathways that exploit relatively high sedimentary layers through the gas hydrate stability zone (GHSZ).

Bear's Paw shows the record of an increase in methane flux from the seafloor which coincided with the relatively dramatic acoustic backscatter signal recorded by the ADCP (Fig. 4, 7). This event was recorded at a site where no active gas emission was detected in the water column by any other acoustic device during cruise SO191. However, signatures of shallow gas at the seep sites including gas blanking and acoustic turbidity were captured with sub-bottom profiles [31], suggesting the presence of subsurface gaseous pockets.

As first shown in Fig. 4, we presented observations of the flare which roughly corresponded to the increase in $\mathrm{CH}_{4}$ flux in the benthic chamber. Fig. 7 is a close up of the backscatter for all four beams. We believe Fig. 7 shows the effects of a

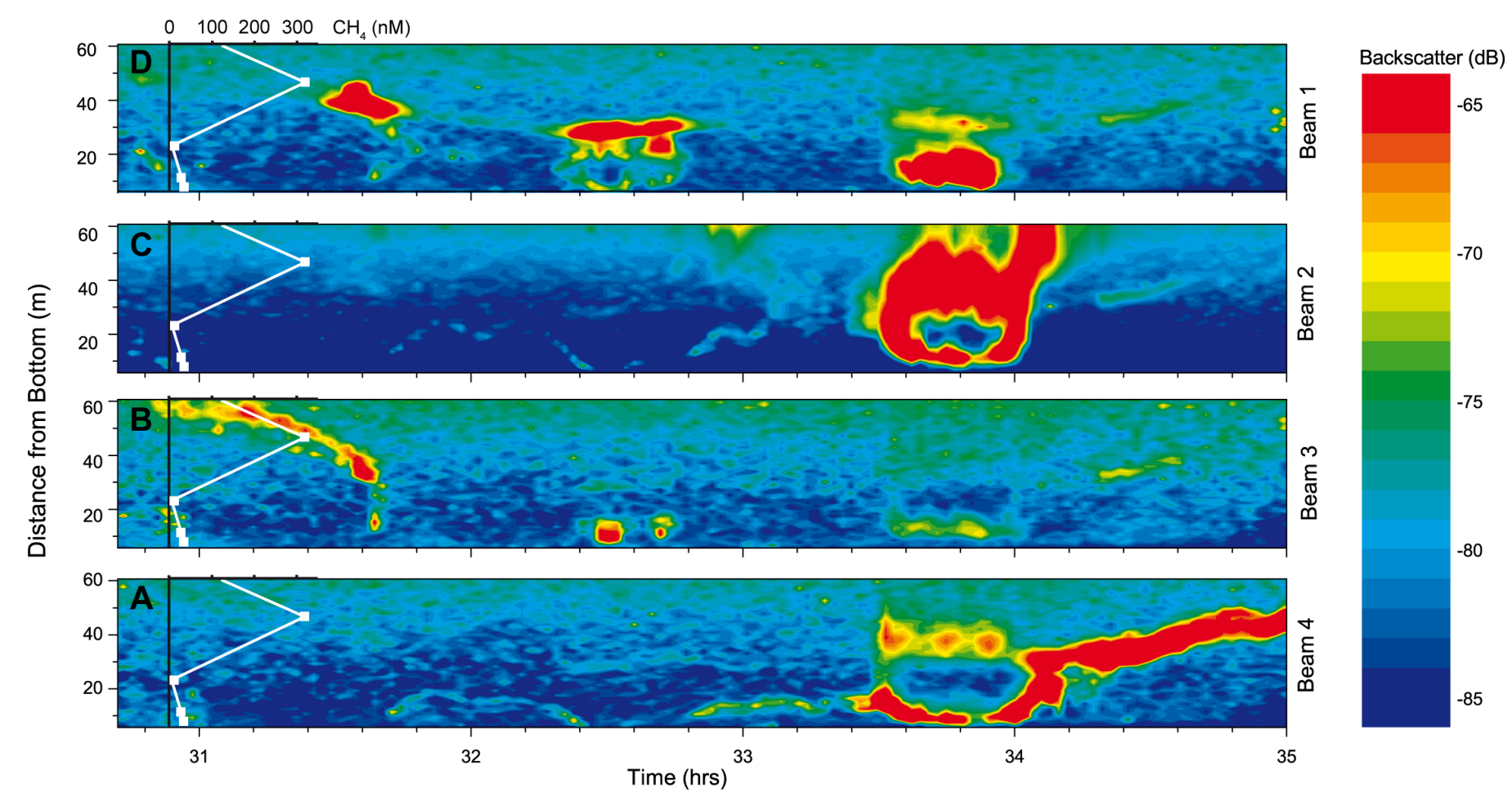

Figure 7. Close up of the ADCP backscatter measurements obtained during deployment of FLUFO-1. Bottom to top: ADCP backscatter A) beam 4, B) beam $3, \mathrm{C}$ ) beam 2, and D) beam 1. Overlaid in white on all panels, $\mathrm{CH}_{4}$ values of CTD cast 18 (conc. values are shown as small numbers ranging for $0-300 \mathrm{nM}$ ). These are arranged so that the peak point $(\sim 300 \mathrm{nM})$ is shown at the exact time it was taken in relation with the ADCP data. 
long-term plume ( $>4$ hours), and speculate that the buoyancy sources are from a combination of high concentrations of dissolved methane in the porewater, perhaps coupled with higher porewater temperatures [33]. The varying intensity of the backscatter signal suggests fluid and intermittent bubble release as well as some light sediment particles. The phenomenon is measured in all four beams, but the long-term "belt" is almost always present in Beam 1 . The very large flare recorded at $33.5-34.5$ hours is thought to be a large bubble outburst associated with the plume source. The flare(s) seems to wander, which is probably due to changing currents, and perhaps spatial variation of the source. Unfortunately, the ADCP data were collected in ENU coordinates, so we are unable to accurately extract individual beam velocities.

The belt-like feature is evident for almost the entire period on panel Fig. 7D (Beam 1), which we assume is related to the local peak in $\mathrm{CH}_{4}$ concentration measured within the belt at about 31.3 hrs during CTD cast 18 (Fig. 7). This methane peak is almost certainly due to a plume intrusion. While it is still difficult to speculate about the source of buoyancy of the plume, we will perform model simulations to try to better define driving forces (i.e. bubbles, heat, dissolved methane, or a combination).

\section{A. Physical Transport of Methane in the Water Column}

In both presented cases, we show strong evidence of a plume. We speculate that these are likely relatively short, intermittent plumes that rise to some distance, which depends mainly on the buoyancy strength and ambient density stratification. The buoyancy source is then depleted, and the plume subsequently detaches from the seafloor. The plume signature (or injection depth), such as high $\mathrm{CH}_{4}$ concentrations, will persist for a certain time ( hours to days) in the water column, but will ultimately be advected away or horizontally and vertically diffusively smeared, depending on the local hydrodynamics. Deciphering the flux pathway of methane across the sediment-water interface is the key in linking physical driving forces, dilution, chemical and microbial oxidation. The type and source strength of $\mathrm{CH}_{4}$ or other buoyancy sources required are therefore investigated using a plume model [33].

The model combines the freshwater plume model [35] with the marine, $\mathrm{CH}_{4}$ bubble model [25], and thermal model [27]. We simulate a (1) methane bubble source, (2) a heat source, (3) a dissolved methane source and (4) dissolved methane source using observed concentrations in the ambient bottom water (c.f. Fig. 6). The plume simulation results below are fairly independent of the initial plume size $(+/-50 \%)$ and are only estimates to see if reasonable buoyancy can be provided to explain our observations.

Run 1 demonstrates that a huge amount of gas is required to produce a plume that rises $\sim 50$ meters high. An gas outburst of $\sim 1 \mathrm{~L} / \mathrm{s}$ methane would be required, however, at $1100 \mathrm{~m}$ depth, this is equivalent to $6 \mathrm{Mol} / \mathrm{s}$, or a gas release rate of $8 \mathrm{Ton} /$ day (however, only for a short period). Run 2 shows a heat source equivalent to a local $2^{\circ} \mathrm{C}$ temperature increase is required to provide the same plume rise height as in Run 1.

The following explanation for Run 3 is diagramed in Fig. 8 . Similar to Runs 1 and 2, for Run 3 we adjusted the initial dissolved $\mathrm{CH}_{4}$ concentration and found that $4.2 \mathrm{mM}$ (roughly $2 \%$ local saturation) was necessary to provide the same plume rise height. This surprising low initial concentration produced a plume rise of $\sim 50 \mathrm{~m}$ with a small source area of $2 \mathrm{~m}$ radius. The final plume concentration in Run 3 is about $463 \mu \mathrm{M}$ at the terminal plume rise height (equilibrium depth), which is distributed over the predicted final plume area of $\sim 50 \mathrm{~m}^{2}$. Water column methane concentrations of $\sim 400 \mathrm{nM}$ [36] were measured in the water column above Omakere Ridge. The final plume in Run 3 would therefore have to be diluted due to horizontal turbulent diffusion and advection to match these concentrations. Diluting the plume by a factor of 1000 (assuming only horizontal turbulent diffusion/dispersion and no oxidation), would imply it spread over an area 1000 times larger. This would mean concentrations in the range of 400 $\mathrm{nM}$ over $50,000 \mathrm{~m}^{2}$ or a circle with radius $126 \mathrm{~m}$ (diameter $250 \mathrm{~m}$ ). Therefore, if a plume 'eruption' or outburst occurred, we would have to sample it within 250 meters to obtain the concentrations observed. This seems on the order of what we could reasonably catch with CTD sampling and in the range of this study (Fig. 8). Of course, higher concentrations resulting in larger eruptions (final concentrations) means we could likely find the methane signals up to a few kilometers away.

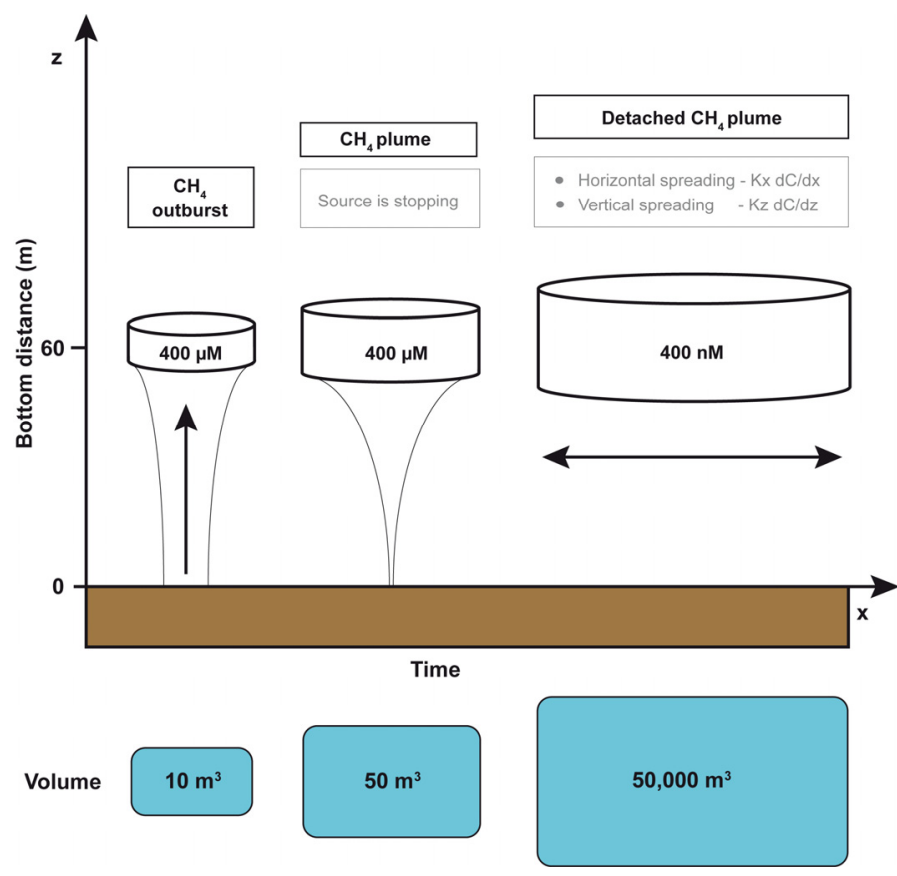

Figure 8. Schematic model illustrating the fate of an outburst which injects a $\mathrm{CH}_{4}$ plume into the water column. After the source has stopped with additional fluid supply the plume detaches from the seabed, spreads horizontally $\left(0.1\right.$ to $\left.0.0001 \mathrm{~m}^{2} \mathrm{~s}^{-1}\right)$ and vertically $\left(1\right.$ to $\left.100 \mathrm{~m}^{2} \mathrm{~s}^{-1}\right)$ which dilutes the $\mathrm{CH}_{4}$ concentration of the enlarging plume. 
If there is no density stratification, then it takes very little buoyancy, and hence, a very low initial $\mathrm{CH}_{4}$ concentration, to cause a plume to rise in the water column as the only resistance is friction (and not density) in this case. This is demonstrated with Run 4 and the well-mixed BBL, where an initial dissolved $\mathrm{CH}_{4}$ concentration of only $200 \mu \mathrm{M}$ could result in a plume rising $3-10$ meters from the sea floor.

Once the methane reaches the water column, it is transported via turbulent diffusion. In stratified environments, the density gradient suppresses vertical mixing. As there are typically no horizontal gradients, horizontal diffusivities are several orders of magnitude larger than vertical.

Rough vertical diffusivities $\left(\mathrm{K}_{\mathrm{z}}\right)$ were estimated from CTD profiles to be $\sim 10^{-4} \mathrm{~m}^{2} \mathrm{~s}^{-1}$ [37]. Horizontal diffusivities, $\mathrm{K}_{\mathrm{x}}$, are more difficult to determine [38], but $\mathrm{K}_{\mathrm{x}}$ values obtained in the literature range from 0.02 to $17.1 \mathrm{~m}^{2} \mathrm{~s}^{-1}$ for lakes, and from 0.3 to over $1000 \mathrm{~m}^{2} \mathrm{~s}^{-1}$ in fjords and the ocean [38, 39]. Methane peaks are therefore diffusively 'smeared' over time. In the vertical, the lifetime of such a $30 \mathrm{~m}$ thick peak can be estimated as $\mathrm{t}=\mathrm{Z}^{2} / \mathrm{K}_{\mathrm{z}}=30^{2} /\left(1 \mathrm{E}^{-4}\right) \sim 100$ days [33]. In the horizontal, if we consider our plume example, the residence time of such a signal is $\mathrm{t}=250^{2} /(0.3-1000)=60$ seconds to about 2 days, supporting the highly ephemeral nature of the methane signals, which disappeared within hours-days.

\section{B. Biological Implications of Water Column Methane}

The observatories that recorded the sudden $\mathrm{CH}_{4}$ increases had been placed at the transition zone between carbonates and dark sediment patches with dense heterotroph ampharetid polychaete beds. These sites, containing mixed chemotroph and heterotroph benthic communities, demonstrate $\mathrm{CH}_{4}$ flux and oxygen uptake rates, which are of the same magnitude as other cold seep systems where chemotroph communities dominate $[15,16]$.

We also discovered that these transition zones exhibit large spatial and temporal variability in the supply of fluids and gases from deeper or neighboring sediments. $\mathrm{CH}_{4}$ may then be discharged into the water column as plumes in an eruptive or outburst pattern that almost completely bypass the benthic filter (e.g. $\mathrm{CH}_{4}$ discharged as free gas would effectively bypass microbial oxidation). Once released into the bottom water this plume is affected by physical processes (turbulent diffusion) which act to dilute and transport it away.

Methane reaching the BBL in dissolved form (via 'plume outbursts' or flux across the sediment-water interface) can be further oxidized aerobically in oxygenated surface sediments or in the BBL where methylotrophic microorganisms might live attached to suspended particles. In general, there are very few measurements of open ocean methane oxidation rates using tracers, so our understanding of the kinetics of microbial methane oxidation in the oxic ocean, particularly in subsurface maxima and plumes, is poorly constrained [2]. However, open ocean water column methane oxidation rates are generally viewed as being quite low, but fractional turnover rates of months [10] and days [40] have been observed with methane concentrations of $\sim 20 \mathrm{nM}$. Ref. [36] calculate a removal rate in the range of 11 to $19 \%$ per day (or $\sim 40$ $\mathrm{nM}$ /day) from the actual variation in $\mathrm{CH}_{4}$ concentrations (< $200 \mathrm{nM}$ ) at one site taking all contribution factors into account. Our model results fall in the same range of magnitude and provide insights into the various processes that come into play when methane is injected into the water column.

\section{ACKNOWLEDGMENT}

We are grateful for the support of chief mate Lutz Mallon, officers and crew of RV SONNE during cruise SO191. Many thanks are due to Bernhard Bannert, Asmus Petersen, Wolfgang Queisser and Matthias Türk for their indispensable technical assistance on board and the operation of the lander technology. We thank Bettina Domeyer, Matthias Haeckel, Sonja Kriwanek, Kristin Krieger, and Regina Surberg for performing the biogeochemical analyses. Thanks to the ROV team of Lieven Naudts, Dries Boone, Marc DeBatist and Jens Greinert and the journalist Dethlev Cordts we were able to visually inspect and document the deployment sites of the landers.

\section{REFERENCES}

[1] P.Forster et al., Changes in atmospheric constituents and in radiative forcing, in: Climate Change 2007: The Physical Science Basis. Contribution of Working Group I to the Fourth Assessment Report of the Intergovernmental Panel on Climate Change, S. Solomon et al., Eds. New York: Cambridge, 2007, pp. 131-234.

[2] W.S. Reeburgh, Oceanic methane biogeochemistry, Chem. Rev., vol. 107, pp. 486-513, 2007.

[3] A. Judd and M. Hovland, Seabed fluid flow, New York, Cambridge, 2007, $475 \mathrm{pp}$.

[4] L.A. Levin, "Ecology of cold seep sediments: Interactions of fauna with flow, chemistry and microbes," Oceanography and Marine Biology: An Annual Review, vol. 43, pp. 1-46, 2005.

[5] A. Lorke, B. Muller, M. Maerki, and A. Wuest, "Breathing sediments: The control of diffusive transport across the sediment-water interface by periodic boundary-layer turbulence. Limnol. Oceanogr., vol. 48, pp. 2077-2085, 2003

[6] S.A. Henrys, S. Ellis, and C. Uruski, "Conductive heat flow variations from bottom-simulating reflectors on the Hikurangi margin, New Zealand. Geophys. Res. Lett., vol. 30, pp. 1065-1068, 2003.

[7] K. Faure et al., "Methane seepage and its relation to slumping and gas hydrate at the Hikurangi margin, New Zealand," N. Z. J. Geol. Geophys., vol. 49, pp. 503-516, 2006.

[8] K.B. Lewis, and B.A. Marshall, Seep faunas and other indicators of methane-rich dewatering on New Zealand convergent margins. N. Z. J. Geol. Geophys., vol. 39, pp. 181-200, 1996.

[9] J. Bialas, J. Greinert, P. Linke, and O. Pfannkuche, FS Sonne Fahrtbericht/Cruise Report SO 191 New Vents. IFM-GEOMAR, Leibniz-Institut für Meereswissenschaften, Kiel, 2007, 190 pp

[10] D.L. Valentine, D.C. Blanton, W.S. Reeburgh, and M. Kastner, "Water column methane oxidation adjacent to an area of active hydrate dissociation, Eel River Basin," Geochim. Cosmochim. Acta, vol. 65, pp. 2633-2640, 2001.

[11] K. Heeschen et al., "Methane sources, distributions, and fluxes from cold vent sites at Hydrate Ridge, Cascadia Margin," Glob. Biogeochem. Cycl., vol. 19, doi:10.1029/2004GB002266, 2005.

[12] A. Nikolovska, H. Sahling, and G. Bohrmann, "Hydroacoustic methodology for detection, localization, and quantification of gas bubbles rising from the seafloor at gas seeps from the eastern Black Sea," Geochem. Geophys. Geosyst., vol. 9, Q10010, doi:10.1029/2008GC002118, 2008.

[13] E.J. Sauter et al., "Methane discharge from a deep-sea submarine mud volcano into the upper water column by gas hydrate-coated methane 
bubbles," Earth Planet. Sci. Lett., vol. 243, doi:10.1016/j.epsl.2006.01.041, 2006.

[14] M.E. Torres et al., "Fluid and chemical fluxes in and out of sediments hosting methane hydrate deposits on Hydrate ridge, OR, I: Hydrological provinces," Earth Planet. Sci. Lett., vol. 201, pp. 525-540, 2002.

[15] P. Linke, K. Wallmann, E. Suess, C. Hensen, and G. Rehder, "In situ benthic fluxes from an intermittently active mud volcano at the Costa Rica convergent margin," Earth Planet. Sci. Lett., vol. 235, doi:10.1016/j.epsl.2005.03.009, 2005.

[16] S. Sommer et al., "Efficiency of the benthic filter: Biological control of the emission of dissolved methane from sediment containing shallow gas hydrates at Hydrate Ridge," Glob. Biogeochem. Cycl. 20, doi:10.1029/2004GB002389, 2006

[17] R. Luff, and K. Wallmann, "Fluid flow, methane fluxes, carbonate precipitation and biogeochemical turnover in gas hydrate-bearing sediments at Hydrate Ridge, Cascadia margin: Numerical modelling and mass balances," Geochim. Cosmochim. Acta, vol. 67, pp. 3403-3421, 2003.

[18] T. Treude, A. Boetius, K. Knittel, K. Wallmann, and B.B. Jørgensen, "Anaerobic oxidation of methane above gas hydrates at Hydrate Ridge, NE Pacific Ocean," Mar. Ecol. Prog. Ser., vol. 264, pp. 1-14, 2003.

[19] J. Greinert, "Monitoring temporal variability of bubble release at seeps: The hydroacoustic swath system GasQuant," J. Geophys. Res., vol. 113, C07048, doi:10.1029/2007JC004704, 2008.

[20] L. Naudts et al., "Active venting seep sites on the gas-hydrate-bearing Hikurangi Margin, Off New Zealand: Visual observations and measurements," Mar. Geol., in press.

[21] K.M. Brown, M.D. Tryon, H.R. DeShon, L.M. Dorman, and S.Y. Schwartz, "Correlated transient fluid pulsing and seismic tremor in the Costa Rica subduction zone," Earth Planet. Sci. Lett., vol. 238, pp. 189203, 2005.

[22] A.L. LaBonte, K.M. Brown, and M.D. Tryon, "Monitoring periodic and episodic flow events at Monterey Bay seeps using a new optical flow meter," J. Geophys. Res., vol. 112, B02105, doi:10.1029/2006JB004410, 2007.

[23] M.D. Tryon, K.M. Brown, and M.E. Torres, M.E., "Fluid and chemical flux in and out of sediments hosting methane hydrate deposits on Hydrate Ridge, OR, II: Hydrological processes," Earth Planet. Sci. Lett., vol. 201 , pp. $541-557,2002$.

[24] I. Leifer, and R.K. Patro, "The bubble mechanism for methane transport from the shallow sea bed to the surface: A review and sensitivity study," Cont. Shelf Res., vol. 22, pp. 2409-2428, 2002.

[25] D.F. McGinnis, J. Greinert, Y. Artemov, S.E. Beaubien, and A. Wüest, "The fate of rising methane bubbles in stratified waters: How much methane reaches the atmosphere?" J. Geophys. Res., vol. 111(C09007), doi: 10.1029/2005JC003183, 2006.
[26] Greinert, J., and D.F. McGinnis, "Single bubble dissolution model - The graphical user interface SiBu-GUI," Environ. Model. Softw., doi:10.1016/j.envsoft.2008.12.011, 2009.

[27] K. Kourtidis, I. Kioutsioukis, D.F. McGinnis, and S. Rapsomanikis, "Effects of methane outgassing on the Black Sea atmosphere," Atmosph. Chem. Phys., vol. 6, pp. 5173-5182, 2006.

[28] I. Leifer, B.P. Luyendyk, J.R. Boles, and J.F. Clark, "Natural marine seepage blowout: Contribution to atmospheric methane," Glob. Biogeochem. Cycl., vol. 20, GB3008, doi:10.1029/2005GB002668, 2006.

[29] E. Suess et al., "Gas hydrate destabilization: Enhanced dewatering, benthic material turnover and large methane plumes at the Cascadia convergent margin," Earth Planet. Sci. Lett., vol. 170, pp. 1-15, 1999.

[30] P.M. Barnes et al., "Tectonic and geological framework for gas hydrates and cold seeps on the Hikurangi subduction margin, New Zealand," Mar. Geol., in press.

[31] A.T. Jones et al., "Acoustic and visual characterisation of methane-rich seabed seeps at Omakere Ridge on the Hikurangi Margin, New Zealand, Mar. Geol., in press.

[32] O. Pfannkuche, and P. Linke, "GEOMAR landers as long-term deep-sea observatories," Sea Technol., vol. 44, pp. 50-55, 2003.

[33] P. Linke, S. Sommer, L. Rovelli, and D.F. McGinnis, "Physical limitations of dissolved methane fluxes: The role of bottom layer processes," Mar. Geol., in press.

[34] G.J. Crutchley, I.A. Pecher, A.R. Gorman, S.A. Henrys, and J. Greinert, "Seismic imaging of gas conduits beneath seafloor vent sites in a shallow marine gas hydrate province, Hikurangi Margin, New Zealand," Mar. Geol., in press.

[35] A. Wüest, N.H. Brooks, and D.M. Imboden, D.M., "Bubble plume modeling for lake restoration," Water Resour. Res., vol. 28, pp. 3235$3250,1992$.

[36] K. Faure et al. "Free and dissolved methane in the water column and the sea surface: Geochemical and hydroacoustic evidence of bubble transport," unpublished.

[37] T.M. Dillon, "Vertical overturns: A comparison of Thorpe and Ozmidov length scales," J. Geophys. Res., vol. 87, pp. 9601-9613, 1982.

[38] A. Lerman, D.M. Imboden, and J.R. Gat. Physics and Chemistry of Lakes. Heidelberg: Springer, 1995.

[39] M.A. Sundermeyer, and J.F. Price, "Lateral mixing in the North Atlantic tracer release experiment: Observations and numeric simulations of Lagrangian particles and a passive tracer," J. Geophys. Res., vol. 103 (C10), pp. 21,481-21,497, 1998.

[40] M.A. de Angelis, M.D., Lilley, and J.A. Baross, "Methane oxidation in deep-sea hydrothermal plumes of the endeavour segment of the Juan de Fuca Ridge," Deep-Sea Res., vol. I 40, pp. 1169-1186, 1993. 